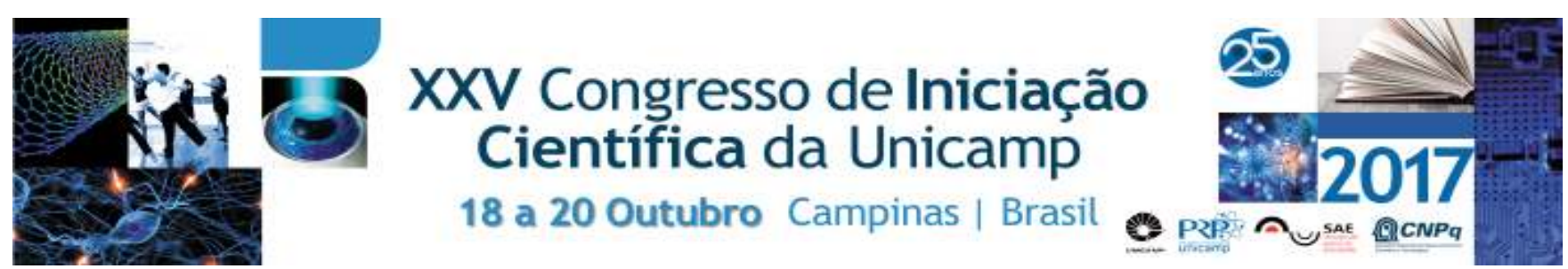

\title{
ADSORÇÃO EM LEITO FIXO DE ÍONS CÁDMIO EM RESÍDUO DA EXTRAÇÃO DE ALGINATO DE ALGA MARROM.
}

Guilherme Fernandes Lopes*, Emily Nishikawa, Melissa Gurgel Adeodato Vieira, Meuris Gurgel Carlos da Silva.

\section{Resumo}

Dentre as tecnologias disponíveis para o tratamento de efluentes contendo metais tóxicos, a bioadsorção se apresenta como alternativa promissora aos processos tradicionais devido à alta eficiência em soluções diluídas e ao baixo custo. Neste trabalho foi investigada a utilização do resíduo da extração de alginato como bioadsorvente na remoção de íons cádmio. Foi realizado um estudo fluidodinâmico em sistema dinâmico para as vazões (Q) 0,$5 ; 0,8$ e $1 \mathrm{~mL} / \mathrm{min}$ na concentração inicial de $1 \mathrm{mmol} / \mathrm{L}$, sendo então definida a vazão de operação em $0,5 \mathrm{~mL} / \mathrm{min}$, enquanto que o efeito da concentração inicial foi investigado para três concentrações (Co): 1; 1,5 e $2 \mathrm{mmol} / \mathrm{L}$, sendo obtidas as seguintes porcentagens de remoção total em torno de $89,5 \%, 89,3 \%$ e $82,8 \%$, respectivamente.

\section{Palavras-chave:}

Bioadsorção, cádmio, resíduo da extração do alginato.

\section{Introdução}

O aumento da industrialização ocasionou o crescente descarte de poluentes prejudiciais ao meio ambiente. Dentre estes se destaca a emissão de efluentes contendo metais tóxicos, com interferência direta no sistema aquático e indireta em outros ecossistemas por biomagnificação. ${ }^{1}$

O resíduo da extração do alginato a partir da alga Sargassum filipendula tem sido investigado como bioadsorvente de metais tóxicos ${ }^{2}$, possibilitando assim um uso mais nobre deste material. Neste trabalho foi avaliado a utilização desse resíduo para a remoção de íons cádmio em sistema dinâmico.

\section{Resultados e Discussão}

As Figura 1 apresenta as curvas de ruptura variando-se a concentração inicial em 1, 1,5 e $2 \mathrm{mmol} / \mathrm{L}$ e variando a vazão em $0,5,0,8$ e $1 \mathrm{~mL} / \mathrm{min}$ respectivamente.

Figura 1. Curvas de ruptura para a bioadsorção de cádmio. (a) Comportamento fluidodinâmico. (b) Efeito da concentração inicial de adsorbato.

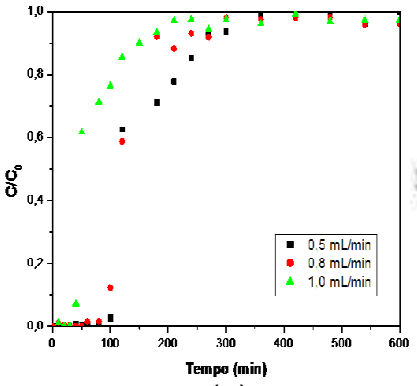

(a)

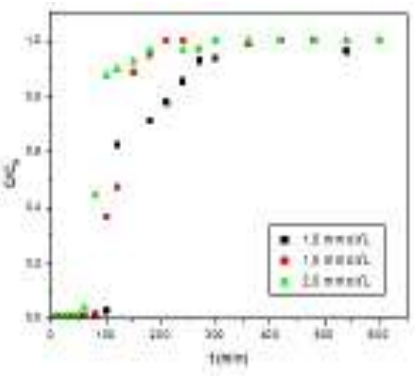

(b)
A partir das porcentagens de remoção no ponto de ruptura e saturação da coluna e pela altura da Zona de Transferência de Massa, ZTM, verificou-se que a vazão mais adequada é $0,5 \mathrm{~mL} / \mathrm{min}$. Pode-se atribuir tal resultado ao maior tempo de contato entre o adsorvente e o efluente, ocasionando maior eficiência de remoção do metal, bem como a ausência de caminhos preferenciais no leito.

Os valores de $q_{u}, q, Z T M, \% R L_{\text {ruptura }}$, e $\% R L_{\text {total }}$ obtidos são apresentados na Tabela 1.
Tabela 1. Parâmetros de transferência de massa calculados para a bioadsorção de cádmio.

\begin{tabular}{|c|c|c|c|c|c|}
\cline { 2 - 6 } \multicolumn{1}{c|}{} & \multicolumn{3}{c|}{$\mathrm{Q}(\mathrm{mL} / \mathrm{min}) ;$} & \multicolumn{2}{c|}{$\mathrm{C}_{0}(\mathrm{mmol} / \mathrm{L}) ;$} \\
\cline { 2 - 6 } & $\mathbf{0 , 5}$ & $\mathbf{0 , 8}$ & $\mathbf{1}$ & $\mathbf{1 , 5}$ & $\mathbf{2 , 0}$ \\
\hline $\mathrm{ZTM}(\mathrm{cm})$ & 2,56 & 2,76 & 4,16 & 2,33 & 2,47 \\
\hline $\mathrm{q}_{\mathrm{u}}\left(\mathrm{mmol}_{\mathrm{c}} \mathrm{g}^{-1}\right)$ & 0,1401 & 0,2278 & 0,1001 & 0,1646 & 0,1647 \\
\hline $\mathrm{q}\left(\mathrm{mmol}_{\mathrm{n}} \mathrm{g}^{-1}\right)$ & 0,221 & 0,3757 & 0,2467 & 0,2468 & 0,2544 \\
\hline$\% \mathrm{RL}_{\text {total }}$ & $\mathbf{8 9 , 4 5}$ & 87,5 & 71,94 & $\mathbf{8 9 , 2 9}$ & $\mathbf{8 2 , 7 6}$ \\
\hline$\% \mathrm{RL}_{\text {ruptura }}$ & 44,99 & 43,66 & 36,09 & 44,61 & 43,11 \\
\hline $\mathrm{t}_{\text {saturação }}(\mathrm{min})$ & 316 & 286 & 276 & 151 & 168 \\
\hline $\mathrm{t}_{\text {ruptura }}(\mathrm{min})$ & 101 & 86 & 37 & 82 & 61 \\
\hline
\end{tabular}

Verificou-se das curvas de ruptura obtidas que o aumento da concentração inicial de adsorbato diminuiu o tempo de ruptura da coluna possivelmente devido aos sítios de adsorção serem preenchidos mais rapidamente, enquanto que o aumento da vazão promove um menor tempo de residência da solução no leito e reduz a eficiência do processo.

\section{Conclusões}

A partir dos valores de ZTM e porcentagem de remoção verificou-se que a vazão mais adequada para os ensaios dinâmicos foi de $0,5 \mathrm{~mL} / \mathrm{min}$. O tempo de ruptura da coluna diminuiu à medida em que a concentração inicial aumentou, sendo o seu maior valor foi obtido para a concentração inicial de $1 \mathrm{mmol} / \mathrm{L}$. As porcentagens de remoção obtidas foram satisfatórias, comprovando a eficiência do uso do resíduo da extração de alginato como bioadsorvente de íons cádmio.

\section{Agradecimentos}

Agradecimento pelo suporte financeiro do $\mathrm{CNPq}$ e da FAPESP (Proc. $n^{\circ}$ 2014/05050-5) para a realização deste trabalho.

${ }^{1}$ Croteau, M. N.; Luoma, S. N.; Stewart, A. R. Limnology and Oceanography 2015, 50 (5), 1511 .

${ }^{2}$ Bertagnolli, C.; Da Silva, M. G. C.; Guibal, E. Chemical Engineering Journal, 2014, 237, 362. 